\title{
Application of natural zeolite for recycling of polymer waste
}

\author{
Yermek Aubakirov ${ }^{1}$, Firuza Akhmetova ${ }^{2-}$, Zheneta Tashmukhambetova ${ }^{1}$, Larissa \\ Sassykova ${ }^{1}$, Ayazhan Kurmangaliyeva ${ }^{1}$, Aizat Gumarova ${ }^{2}$, Kanat Narikov ${ }^{2}$ and Kalamgali \\ Tanakoz ${ }^{1}$ \\ ${ }^{1}$ Al-Farabi Kazakh National University, 71, al-Farabi ave., Almaty, Kazakhstan \\ ${ }^{2}$ Zhangir khan West Kazakhstan Agrarian Technical University, 51, Zhangirkhan, Uralsk, Kazakhstan
}

\begin{abstract}
Recently, the ways of obtaining alternative energy resources in the production of gasoline and diesel fuels have been considered. Using physico-chemical methods, nitrogen and sulfur-containing compounds in gasoline, diesel distillates obtained from polymer residues can be determined. Currently, a promising method is the processing of polymer materials into liquid fuel fractions and organic products. In this method, the destruction of the polymer series with the formation of low-molecular hydrocarbons occurred. The process was carried out at a temperature of $400-450^{\circ} \mathrm{C}$ at atmospheric or elevated pressure in the presence or in the absence of a catalyst. Both pure polymers and various polymer wastes, containing organic or inorganic waste that does not require special cleaning, were used. This technology allows you not only to eliminate wastes, but also to obtain a large number of commercial products.
\end{abstract}

\section{Introduction}

Plastics for various applications are growing every year due to their outstanding benefits, but once used, recycling and recycling remain a challenge [1].

One of the most effective and promising methods of processing and recycling of polymer waste is low-temperature thermal and thermocatalytic destruction. To achieve high efficiency, it is recommended to process wastes in a two-stage method. At the first stage, the destruction of the initial material is proceed in order to obtain a liquid cracking fraction, at the second stage, the liquid intermediate product is hydrogenated to commercial motor fuels.

By considering the regularity of the formation of harmful substances, it is possible to prevent the release of toxic substances into the air $[2,3]$. At the same time, today the process of thermocatalytic hydrogenation is effective for processing polymer waste without damaging the biosphere [4].

By changing the process parameters, it is possible to increase the quality indicators of the product: reducing the cracking temperature and catalyst activity, recirculation of raw materials. However, the parameters can lead to a decrease in the octane number content of

—Corresponding author:firuza.92@mail.ru 
gasoline. For this purpose, a two-stage catalytic cracking technology has been developed: at the first stage, light cracking occurs with a high output of motor fuels, at the second stage, secondary strong cracking occurs on the remaining fractions. Thus, catalytic cracking catalysts can be used in the production of not only high-quality gasoline fraction, but also diesel fuel in order to develop process technology. Currently, new composite catalysts are widely used as catalysts in many technologies [5-7].

Nowadays, catalytic cracking has been considered as the only process of recycling plastic waste. The process is effective and promising. This is due to the fact that it does not require any design changes, and also provides the production of high-octane gasoline and valuable gases with a high yield. For the same purpose, the study of catalytic cracking catalysts is being carried out intensively $[8,9]$.

\section{Experimental part}

The activated zeolite "Taizhuzgen" catalyst has been developed for the resource-saving technology of hydrogenation thermocatalytic treatment of polymer waste in liquid motor fuel.

A mixture of "polymer waste-fuel oil" with a particle size of $2.0-6.0 \mathrm{~mm}$ and a zeolite catalyst "Taizhuzgen"s were used as the raw materials. Natural zeolite of the Taizhuzgen deposit was activated acid-free with $1 \mathrm{M} \mathrm{NH}_{4} \mathrm{Cl}$ solution. The obtained catalyst is $2.0 \%$ of the total mass. The process was carried out in a continuous mixing mode at a pressure of $0.5-0.6 \mathrm{MPa}$ and at a temperature of $450{ }^{\circ} \mathrm{C}$. The practice duration is 15 minutes.

The surface and structural properties of the obtained catalyst were determined by electron microscopy. The morphology of the catalyst sample was analyzed using JEOLJSM 6460LV electron microscopy. Primary and acid-free activated zeolite samples were studied by electron microscopy with an increased value of 10000x. Fine-dispersed free formations of a porous structure are observed on the surface of non-activated zeolite and activated zeolite samples [10].

\section{Results and discussion}

According to its morphology, Taizhuzgen natural zeolite belongs to the amorphous mesoporous phase. The small cubic particles indicate the presence of zeolite structure. The results of the EDX analysis of the catalysts are shown in Table 1.

Table 2. Structural properties of theTaizhuzgen zeolite catalyst.

\begin{tabular}{|c|c|}
\hline Structural properties of the catalyst & $\begin{array}{c}\text { Taizhuzgen } \\
\text { zeolite }\end{array}$ \\
\hline Multipoint BET, m²/g & 6.7 \\
\hline $\begin{array}{c}\text { BJH Method Cumulative Desorption } \\
\text { Surface Area, m²/g }\end{array}$ & 2.1 \\
\hline $\begin{array}{c}\text { BJH Method Cumulative Desorption } \\
\text { Pore Volume, cc/g }\end{array}$ & 0.012 \\
\hline $\begin{array}{c}\text { BJH Method Desorption Pore Diameter } \\
\text { (Mode), } \AA\end{array}$ & 37.4 \\
\hline
\end{tabular}



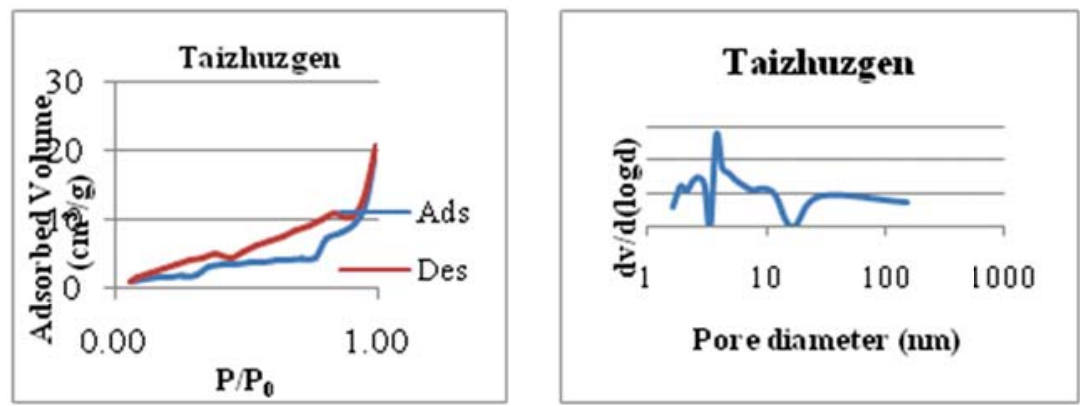

Fig. 1. $\mathrm{N}_{2}$-adsorption isotherm pore size distribution of the Taizhuzgen zeolite catalyst.

The results of the measurement of $\mathrm{N}_{2}$-adsorption/desorption are shown in Table 1 and in Fig. 1. Figure 1 shows the $\mathrm{N}_{2}$-adsorption/desorption isotherms and the pore size distribution of the catalyst. For the catalyst, a sharp increase in the adsorption branch of the isotherm is observed in the region of higher relative pressures. This is due to the multilayer adsorption of $\mathrm{N}_{2}$ in the mesopores of these catalysts. At $\mathrm{P} / \mathrm{P}_{0}$ between 0.30 and 0.40 , an upgrade of the curve is observed, which can be attributed to capillary condensation in mesopores. The sharpness of this curve is an indicator of the uniformity of the pore size distribution. This indicates the adsorption of nitrogen in the small micropores of the zeolite. This shows that this zeolite has more mesopores. The pore size distribution discussed below also confirms this fact. In low-pressure areas, the $\mathrm{N}_{2}$ adsorption isotherm of zeolite is similar to that of type I. However, when the pressure increases, there is a large $\mathrm{N}_{2}$ adsorption characteristic of mesoporous catalysts.
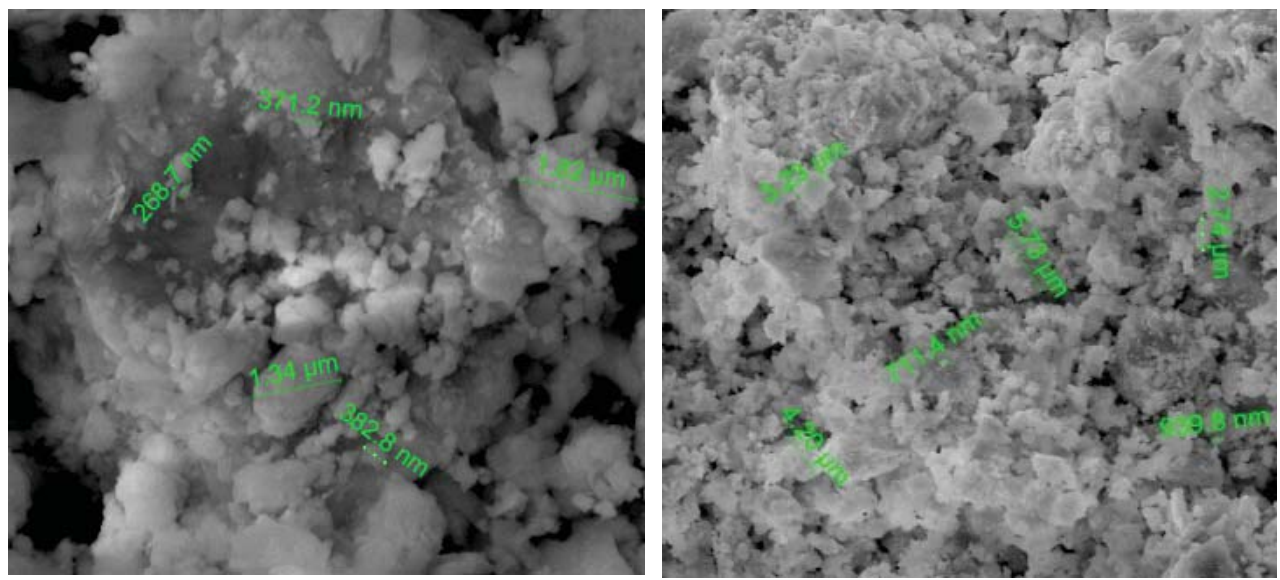

Fig. 2. Electron microscopic image of the zeolite catalyst surface.

The images of activated zeolite obtained by electron microscopic analysis are presented at the magnified scales of $\times 5000, x 30000$.

The nonuniformity of the surface morphology of large-sized particles with sizes up to 5.73 and 1.82 microns at 711.4 and $268.7 \mathrm{~nm}$, respectively, was studied and established on the enlarged scale of 5000x and 30000x.

In general, the catalyst particles show a large-sized granular property. Modification of the surface of the activated zeolite leads to the alignment of the edge and uneven pores. 


\section{Conclusions}

As a result of physico-chemical studies, products were obtained in the presence of the Taizhuzgen zeolite catalyst in the process of thermocatalytic hydrogenation. The products can be used as synthetic motor fuels, which is beneficial for resource conservation. The zeolite catalyst was studied using an electron microscopic analysis method. It has been observed changing the structure affects the activity. The nitrogen adsorption isotherm confirms the presence of mesopores both in the zeolite catalyst and in some microporous regions.

\section{References}

1. V. L. Mangesh, S. Padmanabhan, P. Tamizhdurai, A. Ramesh, J. Clean. Prod. 246, 119066 (2020)

2. J. Santos, A. Pham, P. Stasinopoulos, F. Giustozzi, Sci. Total Environ. 751, 141842 (2021)

3. S. Klaimy, J.-F. Lamonier, M. Casetta, S. Heymans, S. Duquesne, Polym. Degrad. Stab. 109540 (2021)

4. D.P. Serrano, J. Aguado, J.M. Escola, J.M. Rodriguez, L. Morselli, R. Orsi, J. Anal. Appl. Pyrolysis 68-69, 481 (2003)

5. M.E. Abdul-Raouf, N.E. Maysour, A.A.A. Abdul-Azim, M.S. Amin, Energy Convers. Manag. 51, 1304 (2010)

6. K. Kohli, R. Prajapati, S.K. Maity, B.K. Sharma, J. Anal. Appl. Pyrolysis 140, 179 (2019)

7. W.-T. Lee, F.D. Bobbink, A.P. van Muyden, K.-H. Lin, C. Corminboeuf, R.R. Zamani, P.J. Dyson, Cell Reports Phys. Sci. 2, 100332 (2021)

8. K. Kohli, R. Prajapati, S.K. Maity, B.K. Sharma, J. Anal. Appl. Pyrolysis 140, 179 (2019)

9. D. Munir, Abdullah, F. Piepenbreier, M.R. Usman, Powder Technol. 316, 542 (2017)

10. Y.A. Aubakirov, L.R. Sassykova, Zh.Kh. Tashmukhambetova, F.Zh. Akhmetova, Rasayan J. Chem. 12, 1701 (2019) 